\title{
Physically Embodying the Oppressive Trinity: Engaging in Disruptive Identity Praxis as a White Middle Class Male
}

\author{
Charles D. T. Macaulay \\ Sport Management Program, Neag School of Education, University of Connecticut, United States
}

Copyright $(2017$ by authors, all rights reserved. Authors agree that this article remains permanently open access under the terms of the Creative Commons Attribution License 4.0 International License

\begin{abstract}
As an educator in multiple roles who embodies, what I contend is the oppressive trinity while working with individuals who possess identities vastly different than mine, I use this text discuss several practices and praxis that can disrupt the normative standard of American society. First, I discuss how capitalism, racism, and patriarchy operate not as autonomous and separate doctrines, but rather animate and give life to each other and thus should be thought of as one collective ideology as referred to as the oppressive trinity. Second, I discuss autoethnography as an experiential and narrative driven methodological approach incorporated in this analysis. This methodological approach is a unique stylistic and theoretical approach to research, which fuses theory and personal narrative together. Finally, I share a number of practices and praxis I have used to shred the veil obscuring my vision of how the oppressive trinity functions through its physical embodiment, material objects, cultural symbols, and social practices.
\end{abstract}

Keywords White Privilege, Personal Developmental Trajectory, Oppressive Trinity, Autoethnography, Critical Self-reflexivity, Capitalism, Racism, Patriarchy

\section{Introduction}

Our society is becoming increasingly diverse. The likelihood we as researchers, educators, and citizens of encountering someone who possesses different identities then us is significant. However, throughout many organizations we are still playing catchup in terms of reflecting the diversity of our society. For instance, within the United States $82 \%$ of teachers nationally identify as White [1]. Within the realm of higher education $79 \%$ of full-time faculty members (professors, associate professors, assistant professors, instructors, and lecturers) identify as
White [2]. Within a field that I am personally connected to, University athletic departments the numbers inflate across the National Collegiate Athletic Association's Division I administration; $87.7 \%$ of athletic directors, $87.2 \%$ of associate directors, $88.1 \%$ of assistant athletic directors, $91.8 \%$ of faculty athletic representatives, and $92.7 \%$ of sports information directors all identify as white [3].

These statistics matter not only because we are becoming a more diverse society. North America has always been a place of great diversity. However, the numbers I have listed have persisted and have continuously failed to reflect the diversity of this nation. Within the United States, the reasons behind this diversity deficit is a host of historical and contemporary policies, laws, cultural norms and attitudes, values, and social practices that have constructed American society into a highly segregated society.

Many scholars, activists, politicians, pundits point to racial division, some point to class division. There are those who see gender and sexuality as a major component. Within this text I argue that it is not just one of these but rather all of them combined into a form of oppression that I have come to name the oppressive trinity. Specifically, the oppressive trinity refers to the manifestation of capitalism, racism, and patriarchy within our society in the form of a white, middle class, and masculine identity compilation. I discuss how these three, while often separated identities should not be separated but rather, viewed as one identity that not only particular individuals possess but governs our society even when this identity is physically absent.

I raise this argument as I identify as a white, middle class, male who is a graduate student in a Sport Management program at a major research institution, who holds a teaching assistant position as well as a research position. I also work within an athletic department as an academic mentor whose responsibilities are to work with the most academically underprepared student-athletes. In another role, I work with a community-campus partnership program as a boys' leadership program leader within a middle school in a local 
metropolitan area. I bring each of these roles to light because in each of these organizations and roles I work directly with individuals who do not possess the same identities as me. The individuals I work with have had experiences vastly different than mine. These experiences have provided many of them with knowledge and insight into life and society that is nuanced and complex. However, within the realms of education, research, and athletics we tend to dismiss and / or minimize the value of this experiential knowledge.

Therefore, in addition to forwarding the oppressive trinity, I provide a number of praxes and practices I have been introduced to and use to deepen the complexity and nuance of my work as an educator and researcher. Many of us claim to be open minded, educated on the various inequities of our society. However, many of us do not know how to translate that knowledge into information that informs how we engage with others. I hope that drawing on a vast array of resources from a variety of disciplines I can introduce new strategies, praxes, and practices all individuals can use to recognize the oppressive trinity either within themselves or how it is governing their experiences.

\subsection{A Note on Concepts}

Throughout my life and within this text my identities of White, middle class, male have been constructed to illicit what Stuart Hall [4] describes a chain of connotations. I identify as White as my mother is an immigrant from Northern Ireland and my father a several generation Canadian with heritage in Scotland and Italy. While these populations have at one point been considered outside the White racial group, within my life and my parents they have been integrated into the White racial category. As such, when I use the concept of White, I am referring to my familial heritage in Northern and Western Europe but I am also referring to my ability to identify with the larger White historical narrative of a Western tradition of thought tracing civilization from Greco-Roman expansion through to British Imperial rule to the subsequent nation-states birthed in this Western tradition despite preexisting social and political structures.

The chains of signifiers I often associate with my middle class identity are economically defined. My father is a lawyer while my mother was a university administrator and now a small business owner. While money was always something my family was cognizant of, this was due to the lack of complacency of my parents. Rather than being satisfied with the home we lived in, I have been raised in perpetual renovations. When younger I confused this tight family budget with economic hardship but have since realized the economic advantage my family possessed. The combined prestige of both my parents' titles as lawyer and business owner and the financial remuneration of those positions has allowed for material comfort in several ways including homeownership, owning cars, new furniture, etc. while we, as a family, continue to be financially cautious.
Thus, when I refer to the concept of middle class, I am alluding to a material and financial comfort that includes having necessities such as housing, food, clothing, transportation, and in addition, allowing for other non-essential material comforts such as renovations, technological gadgets.

Finally, my male identity should be read as heterosexual cis-gender male. I was born and identify as both biologically male as well as socially. Further, I am aware I tend to subscribe to the hegemonic masculinity persistent in North America. I grew up playing hockey outdoors, and even though we lacked the 'proper' equipment blocking shots, hitting, and even fighting were still common practices we did not shy away from. It is a mentality that I often bring into activities to this day, such as playing pick-up basketball or having to pull long nights of paper writing; it's a testament to my toughness. Participating in this practice along with many other sports has instilled a sense of athleticism, strength, and emotional grit within me that I most associate to masculinity and being a man. Therefore, the concept of male should not only read as physiologically a man, but also indicate a form of hegemonic masculinity rooted in strength, grit, and emotional control.

The purpose of this description is to engage in a personal development trajectory exercise as a continuation of my own critical self-reflexive practices [5]. I have chosen to pursue forwarding the idea of the oppressive trinity and various praxis' for understanding how the oppressive trinity operates within each of our lives through an autoethnographic writing methodology. I theoretically contextualize the oppressive trinity within my own experiences. The three ideological structures of capitalism, racism, and patriarchy inform each other to insure hierarchical structures predicated on race, gender, and wealth, govern our society through social practices, material objects, and cultural symbols.

As I have engaged in the praxes and practices I describe below I have become more attune to the experiential knowledge many of those I work with possess. This has deepened the complexity of my research and strategies as an educator. I do not claim these praxes will or have deconstructed my privileges, but they have allowed me to gain an awareness of my positionality. Through this awareness not only have I been able to thicken my research and educational strategies, I have been able to leverage my privilege for mitigating the influences of the oppressive trinity and promoting social justice and equity. Substantive change to the larger systems of oppression can only manifest if we are aware of how oppression is embodied in ourselves and how it is perpetuated through our thoughts, actions, and inactions.

\subsection{Purpose of This Text}

Engaging in this praxis is accentuated for two reasons. First, I reflect the national trends of individuals who identify as white in positions of authority within educational settings. 
Second, like many educators, who possess the same identities, I work with individuals who identify as Black, African American, Latinx and are from disadvantaged economic backgrounds. As a teaching assistant at my current university the classes I work within predominantly includes students who self-identify as white, which reflects the larger trend of the university[6] as well as major research institutions across America [7]. However, within the athletic department, I work with individuals who identify as African-American and specifically with a team that is comprised of approximately $50 \%$ African-American or Black student-athletes, which is about 10 times the proportion of African-American students on campus; there is a profuse amount of literature discussing and documenting the problematic nature of this disproportionate racial representation in athletic spaces. Within the middle school, the community-campus partnership organization is located and where I oversee a boys' leadership program, a $100 \%$ of the students identify as African-American, Black, and Latino. In addition, both the college student-athletes and the middle school populations primarily come from economically disadvantaged backgrounds.

As one may have noticed, the identities of those I work with and myself are different in pronounced and significant ways. Although, this does not mean we are unable to work together, there is a need to recognize each other's identities, as it is our identities that shape how we perceive, understand, and navigate the world. As an individual who wants to be an educator and believes in the equitable distribution of resources and inclusive decision making practices (captured in this text in the concept social justice practices) interrogating the identities I possess and privileges attached to those identities is important. In addition, choosing to engage in relationship building rather than relying on titles has been an important component in becoming an equitable and inclusive program developer, researcher, and educator.

Finally, engaging in these practices I have become aware of the experiential knowledge the individuals I work with possess. While they may not have the same understanding of the world as I do, as a White middle class male (WMCM), the way in which they understand the world is highly informative and provides opportunities for all of us to challenge hegemonic norms that operate to maintain unjust social hierarchies based on the oppressive trinity in our society.

The purpose of this text is to highlight how critical self-reflexivity can be a powerful tool in reconceptualizing meaning and pushing theoretical limits. Bell hooks in several of her essays within the Teaching to Transgress discusses how multiculturalism washed over academia bathing it with a desire to include texts and voices other than dead white men's. However, like a wave it retreated back to the ocean leaving puddles and ponds here and there. It is within that conglomeration of texts hooks describes a need for educators to be self-actualized individuals. It is my hope this piece will present several tools and exercises that will have the power to spur the growth needed in all of us to engage in more effective strategies for disrupting the oppressive trinity and its visceral effects on society at large and in particular on groups who are oppressed. It is my hope that the strategies presented here are adopted, by those who read this, as a tool to inform their research and educational strategies. Understanding the oppressive systems are one thing, recognizing how those oppressive systems manifest themselves within ourselves can be difficult and uncomfortable. However, the strategies discussed below are meant to help inform how we move from understanding to recognizing.

\subsection{Goal of This Text}

It is the goal of this text to highlight how the inseparable ideologies, the oppressive trinity, of capitalism, racism, and patriarchy inform our identities through my own experiences. I will discuss a number of theories which have provided strong foundations and theoretical frameworks through which I develop my argument including intersectionality and systemic racism theory (SRT), among others. In addition, I will discuss a number of theoretical praxis' including Peggy McIntosh's praxis of unpacking white privilege, Paulo Freire's notions of needs based education, and Latino/a Critical Theory's (LatCrit) and Critical Race Theory's (CRT) vindication of alternative epistemologies which have allowed me to lift the veil shrouding the link between my identities and the oppressive trinity.

The oppressive trinity is an ideological discourse prevalent throughout North American society and various parts of the globe (e.g., colonialism, imperialism, etc.). It manifests itself not only in the physical presence of individuals possessing the oppressive trinity identities, but evinces itself through social practices, cultural symbols, and material objects.

Within this paper I share with the reader the structural forces and personal experiences which shaped my identities and how I came to understand and recognize the inseparability of these entities. I hope sharing these experiences I have had and practices I engage in will encourage others to do the same as we strive to be socially just and liberating researchers and educators.

\section{The Oppressive Trinity: Capitalism, Racism, and Patriarchy}

Within American society the hegemonic norms governing our society are informed by the ideological structures of capitalism, racism, and patriarchy. These three ideological structures do not just inform the larger institutions of society, but rather permeate every organization, relationship, and individual. They inform how we organize ourselves geographically, economically, educationally, and so forth. These three inseparable ideologies have informed American 
society, and large swaths of other societies, to the point they should be recognized as one entity when considering their impact on who we are as individuals and how we organize our society. I state my identities, white, middle class, and male not only to interrogate them through the theoretical praxis', but also to highlight how these identities are indicative of the powerful normative standard that exists in our society. As such, I argue the power these ideologies possess throughout our society (social practices, cultural symbols, and material objects) have real implications for the perpetuation of inequalities as well as covert and overt resistance against alternative ideologies that could lead to more empowerment among groups that are disadvantaged, marginalized, and oppressed.

\subsection{Intersectionality; a Starting Point}

The Christian trinity of the Father, Son, and Holy Spirit are believed to be one entity. While often discussed separately there is an understanding these three are the same entity, informing and giving life to each other. The trinity of capitalism, racism, and patriarchy very similarly exist together at once, informing and giving life to the others. Kimberle Crenshaw's [8] conceptualization of intersectionality provides a strong starting point to capture how these three ideological doctrines give life to each other. In that seminal piece, Crenshaw describes the intersectionality of race and womanhood as a traffic intersection wherein cars passing through are traveling opposite directions and from multiple directions. This conceptualization has expanded to include all identities an individual possesses. Furthermore, it allows individuals to interrogate how their identities inform and contribute to their lived experiences [9]. For instance, "analyzing the multiple ways that race and gender interact $[\ldots]$ revealing the processes by which grassroots organizations shape advocacy strategies into concrete agendas that transcend traditional single- axis horizons"[9]; or how an individual's race, class, and gender may affect educational practices and life outcomes.

However, intersectionality starts from locating the identities one possesses and how those identities shape an individual's interaction with the world. Through interrogating these interactions one can begin to see how their identities are informed by society as well as guide one's interactions with it. The strength of intersectionality is its recognition that we all possess multiple identities and the combination of identities provide unique experiences. For instance, Crenshaw [10] discusses a case against General Motors in her original piece highlighting how Black women were placed at an economic disadvantage due to both their race and gender (e.g., lower pay than their White counterparts, fewer opportunities for upward mobility, etc.).

While the introduction of intersectionality as a theoretical approach has been instrumental in the commencement of much richer and deeper theoretical and empirical investigations regarding power structures I am advocating for a soldering of three often theoretically independent doctrines of capitalism, patriarchy, and racism. These three doctrines have created a normative standard in North American society, which has manifested in a white middle class male standard. It is not about the intersection of these three identities, as they appear in the individual rather it is the ever-presence of the oppressive trinity identity as the overarching standard of American and Canadian society. An individual may not possess a single one of these identities, but they will be judged and held accountable to the oppressive trinity even in its physical absence.

\subsection{Expanding Systemic Racism Theory}

This omniscience of the oppressive trinity is saturated throughout our society. Feagin in Systemic Racism: A theory of oppression [11] provides a theoretical approach to understanding the racist structures governing America. Examining slavery, legal segregation, and present day inequalities Feagin highlights how racism is systemically intertwined within every facet of American society. This racist structure America is founded on and continues to be informed by has created a system that has benefited individuals who are White from the colonial conquest of the Americas to present day North American society.

Systemic racism theory includes several tenets: a) unjust enrichment of whites and the unjust impoverishment of blacks, b) the white racial frame, c) socioracial hierarchy with divergent group interests, d) alienated social relations, e)extraordinary costs and burdens of racism, and f) constant struggle and resistance[12].

\section{The Unjust Enrichment of Whites and Unjust Impoverishment of Blacks}

This tenet focuses on how we, White people, within America have benefited both politically as well as economically through the use of violence, theft, oppression, and racial discrimination. This has occurred through the legal enslavement of individuals who identify as Black and has continued throughout ever period since emancipation albeit in an evolved form [13]. Today, this manifests itself in a number of ways. The prison industrial complex is one well cited example however, it is also exhibited in the unjust educational practices found in top National Collegiate Athletic Association (NCAA) university athletic departments whereupon student-athletes are provided a meager educational experience in return for the millions of dollars made from their participation in their sport[14].

\section{The White Racial Frame}

This is the subjective lens coloring how we, White people, view and understand the world. This lens is, "an organized set of racialized ideas, stereotypes, emotions, and inclinations to discriminate" [15]. This frame informs how many individuals interpret the world and make sense of 
situations in American society. Referring back to the athletic example, many of us, White Americans and Canadians with European ancestry attribute the preponderance of African American or Black athletes in basketball and football as "naturally" gifted athletically. Even when challenged with the realities of Whites excelling in other sports like soccer, swimming, and hockey, and the lack of dominance in international sporting events like the Olympics by African nations, the skewed rationalization within the white racial frame seeks to create an understanding that does not critically interrogate is clear hypocrisy.

\section{Socioracial Hierarchy and Divergent Group Interests}

Within North American society a hierarchy of groups has been constructed based on physiological attributes like skin color. This has placed us, white people, at the top of the hierarchal order and is exhibited through the systemic disadvantaging of racial groups deemed as non-White or "Other" [16]. For instance, redlining African American and Black communities due to perceived risk of individuals who identify as African American and people who identify as Black $[17,18]$. This has led to the continued impoverishment of this group of people while White families have been able to accumulate wealth over several generations.

\section{Alienated Social Relations}

The divide between the majority of White and Black, Latina, Asian, Native American, and Indigenous groups of people has alienated these numerous groups into hierarchal social relations. This has almost been entirely accomplished through the actions of my racial population with the express purpose of maintaining hierarchies of wealth. Bacon's Rebellion can be pointed to for the importance of this alienation. Bacon's Rebellion is one of the last multi-group rebellions that occurred prior to prioritizing the formal legalization of racial division in all aspects of society. Bacon's Rebellion of 1676 is most pointed to for the variety of groups that took part within the revolt, which included White indentured servants, Black slaves, and peasant women of all three groups [19]. After the suppression of the revolt the ruling elites in this case, White landowners or what was known as the leisure class, took several measures to codify racial privileges. This included taking slow but measured steps in the legislature to increasingly make it more and more difficult for both African slaves and Native American slaves to escape bondage while the indentured Whites who had fought hand-in-hand with these groups of individuals were raised from servants and peasants to positions of authority over the slave population of Africans and Native Americans [19]. The ruling elite understood the importance of dividing and conquering populations in order to maintain rule.

This divide along skin color and what became racial pseudoscience still informs our society today. It informed Jim Crow and countless other laws throughout America on the separation of individuals based on race. It informed redlining post-World War II [20, 21]. And it continues today in the form of racialized disciplinary measures in education from kindergarten through university and beyond [22]. Today, America's communities are less diverse then during the Civil Rights movement [23]. This is due to the alienation of groups of people based on race through legislature enacted in 1600s and continues to create a cultural and economic divide that limits and cuts off any ability to interact with different perspectives and approaches to understanding the world.

\section{Extraordinary Costs and Burdens of Racism}

Being attributed or identifying as an Other whether it be that of Black / African American, Latinx, and/or Native American places a burden on an individual not held by me and other White people. We are only now beginning to understand the impact microaggressions and racial inequities have on individuals' health outcomes [24]. These microaggressions coupled with the systemic racism embedded within our society not only negatively impacts their quality of life, but also literally takes years off the lives of individuals who identify as Black / African American, Latinx, and Native American.

\section{Constant Struggle and Resistance}

Any narrative forwarding the complacency of Black / African Americans to their enslavement and continued discrimination in American society is factually false. From the moment African Americans have been forcefully brought to the Americas there have been revolts, dissenters, intellectuals, political leaders, religious men and women, activists who have all actively and tirelessly fought for the liberation of Black people both nationally and internationally.

\section{Expanding SRT to include Gender and Capital}

Utilizing various narratives of individuals from the time of slavery, segregation and present day, Feagin [25] shows us how these theoretical concepts manifest in society. However, Feagin predominantly focuses on race as the primary reason for the inequalities and injustices pervasive in our society. Although, Feagin states, "white-on-black oppression is an independent social reality that cannot be reduced to other social realities such as class stratification, though all major forms of oppression do interact and intersect with it historically", I argue class and patriarchy are not forms of oppression that interact and intersect with but rather are animating and informing racism as racism is informing the other two tenets of the oppressive trinity.

Nell Painter [26], an American historian, discusses the idea of Blackness within American culture. She states, Blackness will, for the foreseeable future, be associated with poor dark-skinned people. While Painter is describing the connotations associated with blackness it is in conversation with its dichotomous partner, whiteness. It is as Hall [27] describes race as a floating signifier, "which can be linked to other signifiers in a representation. Its meaning is relational 
and it is constantly subject to redefinition...". However, Hall also states that race has a reality and within the American context that reality is Feagin's recognition of the material, psychological, and physical benefits being granted to whites.

However, I bring Hall to the fore here because of his contributions on signifiers. To clarify, a signifier is a "signal in the physical or social world that can be interpreted..." [28]. For Hall signifiers are floating. They are not concretely attached to the material world and therefore are able to and do change. Hall also notes that these signifiers are not singular. They do not denote one meaning. There are numerous connotations linked as if part of a chain that exists in tandem with signifiers. Race, as Painter describes, is a part of a series of connotations including poverty.

Therefore, race is much more than just the skin color of an individual. It is much more than the intellectual and physical mediocrity attributed to Whiteness. White and Whiteness unfurls a chain of middle class and masculine linkages. These chains should not be thought of as singular strands, but rather one single strand looped and connected informing and giving life to each other. It is through a number of aspects that these chains are generated and maintained within the individual and throughout society. Physically, the oppressive trinity exists in the bodies of those who possess the identities it has come to manifest itself in. How we act and what we view as credible social practices. The material environment we construct and objects we surround ourselves are constructed in a way to benefit those who possess the oppressive trinity. And finally, the oppressive trinity operates and manifests itself within cultural symbols we employ throughout society.

While intersectionality allows an individual to identify multiple identities that inform and define an individual's experience, that experience is always in relation to the oppressive trinity no matter what the identity composition. It is always in relation to the oppressive trinity because the oppressive trinity is systemic in our society. In every facet, physical, material, social, cultural, we find the oppressive trinity governing.

\subsection{Oppressive Trinity as Physical Embodiment}

Butler (1993) discusses the materiality of the dominate body within, Bodies that Matter. Within this text Butler describes the construction of the body, or the material, as something that only belongs to the properly propertied, racialized, and masculinized body. All other bodies that fall outside of these necessary prerequisites lack form and therefore lack rational humanity. In other words, if an individual does not possess these requirements they do not fall within the notion of humanity. It also places the idea of the material in relation to the immaterial. Specifically, the body is shaped by the ideological structures that exist. Butler asks, "if a bodily schema is not simply an imposition on already formed bodies, but part of the formation of bodies, how might we be able to think the production or formative power of prohibition in the process of morphogenesis?" Thus, the body develops based on the structures informing the body. It is not born a signifier rather it is shaped into a signifier.

It is through social practices, material objects, cultural symbols that the physical body becomes informed as a signifier. This embodiment is cultivated within an individual well before they are even born and therefore makes it impossible for an individual to avoid. Prior to birth, here in North America, the material objects, cultural symbols, and social practices constructed and maintained shapes the environment in a physical and psychological way to ensure that when an individual is born with little to no melanin in their skin, with the biological parts of a man, and are raised within the middle class or higher you come to physically embody the oppressive trinity. Being born without these prerequisites translates results in a criticism, battering, repression, even erasure under the weight of the oppressive trinity standard of operation and approval. For instance, there are measurable differences in health conditions based on the material, gender, and racial comforts afforded to those who possess oppressive trinity.

In the 2008 documentary, Unnatural Causes [29], which examined how economic and racial implications affected health outcomes, it was found that individuals living in low-income neighborhoods experienced shorter life spans. The average age of death continued to lower when race was considered. Further, according to Mansukhani, et al. [30] there is a severe under representation of female subjects within medicinal research. This has led to serious health status, disease presentation, pathophysiology, and therapeutic response implications. The disregard for sex when conducting preclinical trials has created a gulf in clinical research that has had serious repercussions within society. For instance, there has been little research conducted on pregnant women who fall ill. The majority of the time Doctors prescribe medicine at dosages for women (who are often under represented during clinical trials) who are not pregnant nor trying to get pregnant. These examples show the value placed on the body that possesses the biological and physiological attributes needed to be acknowledged as human within the socialization process. All those who fail to be born without these characteristics, as Butler argues, fail to be recognized as a legitimate form.

\subsection{Oppressive Trinity as Social Practice}

As already alluded to the physical embodiment of the oppressive trinity doesn't just occur, rather it is exhibited through a number of other cultural components. Social practices are the (un)conscious, (un)intentional, knowledgeable social actions and interactions that constitute our daily lives [31]. For instance, the division of boys and girls within children youth sport leagues is a conscious, intentional social action that informs and guides how we think about gender norms within our society.

We can actually turn back to Feagin's [32] text where he 
provides a multitude of historical and contemporary examples of social practices that have been and are engaged in throughout society. He also alludes to how capitalism, racism, and gender are connected, but does not outright claim that these three doctrines are integrally connected. I have explicitly listed some of these examples that demonstrate the oppressive trinity operating as social practice:

“Chestnut's [a slave master's wife] questioning of slavery, doubtless like that of numerous other white women, seems mostly to have been out of fear of black rebellion and because of bitterness about what slavery had done to white 'wives, children, and families of the masters, as well as to the masters themselves.' In her writings, she discusses with great disapproval the black 'mistresses' and 'mulatto' children of many white men, including plantation owners she knew [...] They [white women] were upset at the way in which the patriarchal system held white women under puritanical restrictions" (pg. 118).

In this example, we can see the oppressive trinity working during slavery in the United States albeit impacting various groups differently. While a white woman and therefore free, she was not economically free nor did she have the same freedom as her white male counterparts due to the 'puritanical' rule of the patriarchal system that existed. In juxtaposition to this is the freedom provided white men with wealth to transcend race and have extramarital affairs without them facing repercussions for these transgressions. Here we see whiteness operating as a racial privilege providing limited freedom. It is the addition of class and gender privileges that allows these individuals to act as they did constituting the cultural norms of society at that time. Further, these hyper-aggressive sexualized acts conducted by White males during slavery is one social practice constituting not only the vile institution of racial slavery, but this social practice of using sexualized violence demonstrates the privilege afforded to individuals who embodied the oppressive trinity.

In an earlier piece Hall [23] discusses State power functioning through the condensation of multiple domains. Through this condensation of norms, values, and practices the State transforms each of these into forms of domination. Thus, Hall argues, the State exercises its power through a difference in unity. Whiteness provides some freedom, wealth provides others, and gender others. However, condensed into one and exacted over society through the enacting of social practices, material objects, and cultural symbols; capitalist, racist, and patriarchal rule maybe theoretically independent, but in reality, operate as one.

This next example coupled with the previous demonstrates the normalization of the oppressive trinity standard;

"Moreover, as I noted in chapter 3, for centuries most white men have viewed themselves as 'virtuous republicans,' as religious, moral, and civilized. Early white male colonists portrayed
European Americans as rational, ascetic, and sexually controlled, while Black Americans and Native Americans were stereotyped as uncivilized, hedonistic, irrational, and happy-go-lucky" (pg. 178).

Previously we saw white men engaging in extramarital affairs that involved the raping of Black women. However, these violent stereotypical tendencies were placed on the image of Black men. This further contorted the connotation attached to men with darker skin color and their identities while exonerating White male bodies and identities from the crimes they had committed. Through the construction of these narratives that manifested in plays, novels, images, and social relations the WMCM standard of respectability and prudence came to be the norm.

Unfortunately, this narrative has not ceased to exist. While a religious, moral, civilized, and sexually controlled narrative is part of the chain of connoted signifiers for the oppressive trinity historically, the United States of America has elected White men to political office who have failed to fulfill this narrative. The extramarital affairs of both John F. Kennedy and Bill Clinton, while not the systematic use of rape against Black women and the entire Black community, were not overly consequential for these two individuals. To a degree both men are idolized despite these actions. What the actions of these two white, middle to upper class, men exhibit is how the oppressive trinity informs sexual activities as social practices.

For instance, shifting our focus to a present example, examining and comparing the case of Corey Batey and Brock Turner exemplifies how the oppressive trinity skews the narrative of sexual social practices. In the former case a Black male football player was found guilty of what the judge described a morally reprehensible act [34]. Corey Batey was convicted of raping a young woman while she was unconscious. There was an outstanding amount of evidence including a video of the rape in progress. The judge sentenced Corey Batey to 15 to 25 years in prison. In the latter case, Brock Turner, a White male swimmer was caught in the act of raping an unconscious woman behind a dumpster [35]. The jury found him to be guilty. The judge presiding over this case believed sentencing Brock Turner to "a prison sentence would have a severe impact on him".

Here we see the privileges attached to the physical embodiment of the oppressive trinity in full operation. One may argue sexualized violence is a social practice all men are encouraged to participate in. I argue the oppressive trinity minimizes and out right neutralizes the severity of these actions among individuals who do embody the oppressive trinity which places an extraordinary cost and burden on anyone who does not.

\subsection{Oppressive Trinity as Material Object}

Today, whiteness, wealth, and masculinity exhibit itself in the identities of WMCM and the systems which perpetuate the privileges attached to those identities. The great detail 
provided by Feagin in his text is worth exploring, but nonetheless these examples allude to class and gender not just intersecting but also informing how individuals have and continue to act and navigate through the world. The oppressive trinity does not exist only in its physical manifestation in the bodies of white people and social practices, it also exists in many material manifestations.

Here material objects will be the inorganic substances that have been shaped and transformed into the physical environment. This includes things many of us would consider as insignificant such as clothing to the buildings and roads that direct where we go and how we get there. We live in a material world, as it is the physical environment that truly shapes a great deal of who we are and what we engage in. However, we are not only a material world, the organic material of our bodies and untouched nature, the social practices we engage in and the immaterial also operate to constitute our world.

The material objects that construct our world are imbued with the oppressive trinity, which have intra- and intergenerational impacts. For instance, the Home Owners Loan Corporation (HOLC) instituted by Franklin D. Roosevelt. This program, which was designed to appraise the value of homes, included the race and class of the homeowners and residents of the neighborhood when determining property value $[36,37]$. This created a spectrum of color coded maps that designated value of land based on the race and class of the residents composing the neighborhood and not the physical condition of the property. This system has become widely known as redlining affectively inflating the value of White, middle class family homes and neighborhoods due to their possession of the oppressive trinity.

Although discriminatory housing practices are not allowed today we continue to see the effects of these practices. Families who were able to create wealth through property ownership have been able to leverage the wealth in their property ensuring they are able to remain in desirable neighborhoods. This has resulted in the economic mobility of individuals who are white to leverage their family's economic stability to be able to afford university through family support and / or economic support while transitioning out of higher education and into an occupation.

\subsection{Oppressive Trinity as Cultural Symbol}

A key aspect of any society is the symbols used to convey meaning. These symbols can and do manifest in physical objects however their meaning exists beyond the physical object they are present in.

A great example of a cultural symbol is the presence of the WMCM normative standard within testing. Mercer [38] found standardized testing, was written in the language of the dominant culture. This finding has been reinforced by Zoref and Williams [39] who found that multiple standardized tests were both sexually and racially imbalanced. Although, these tests are material in nature, putting pen to paper and filling out a bubble sheet, the symbolic importance of standardized tests is what carries importance in American society. The score an individual receives on a SAT score or other college proficiency exams symbolizes their competency within that given culture. The GPA works similarly. Individuals work hard in order to obtain and maintain a high GPA throughout their educational career. However, the GPA acts as more of a symbol of one's success and knowledge without an actual demonstration of an individual having to demonstrate their knowledge. Further, a GPA of a student from an urban school does not carry the same weight as a GPA from a suburban school. While these indicators of success may be useful to determine preparedness, they are also loaded with meaning that goes beyond competency.

However, individuals who are white, middle class, and male and have been established to reward individuals who act and think similarly to these standards. Within our school systems children who are able to perform according to a white standard of thought are rewarded while suppressing other forms of participation and knowledge. High disciplinary and suspension rates for individuals who identify as non-white shows how this standard is punitively enforced [40]. There is often a lack of respect for the way individuals from different backgrounds may approach and solve problems. There also becomes a myopic concentration on test scores as the measure of success rather than focusing on incremental learning. Educators focus on teaching children the right way to write essays based on western tradition rather than recognizing the variety of expression for complex thought through the written word.

In summation, the oppressive trinity is the presence of capitalism, racism, and patriarchy as a single entity manifesting itself through physical embodiment, social practice, material objects, and cultural symbols. The oppressive trinity through the normalization of white, middle class, masculinity has created a system where the oppressive trinity is present in every facet of our society. Even when it is absent how our society is arranged and organized means that the oppressive trinity is ever present.

\subsection{Oppressive Trinity a Present Example}

A recent example of the prominence of the oppressive trinity informing a WMCM normative standard in our society is pointing to the 2016 U.S. presidential election results. Even prior to the final votes being counted for the presidential election on Tuesday, November 8th, 2016 the political pundits, strategists, satirists, and anyone with access to social media began to dissect the results and pinpointing how Former Secretary Clinton lost. While it is a much more complex discussion then I am going to explore here, we have been fed the narrative that Former Secretary Clinton did not resonate with the white, rural, and poor who ultimately handed Trump the traditionally democratic rust belt. However, examining the exit polls posted by the New York 
Times [41] provides a different perspective. The numbers listed via the New York Times suggest not an underclass of whites voting for Donald Trump rather a middle class white population that is disproportionately male. These numbers stand out even further when comparing the exit poll data for Former Secretary Clinton, who won the working class vote, but was several percentage points below Trump when it came to voters who earned $\$ 50,000$ or more.

The narrative of poor white Americans struggling in the heartland is not why Donald Trump won the election. I contend the data showing the results of this election were not just a race issue or a class issue, or a gender issue, but rather it exemplifies the oppressive trinity in operation. This is white men who make middle class wages / salaries fearing the standard of American society is at risk, threatening the comfort their embodiment of the oppressive trinity affords them. Whiteness cannot be separated from class and masculinity in North America. They inform each other, breathing life and animating themselves, and operate as a single entity. Whether it is through the social practices of sexualized violence against women to the election of a xenophobic, Islamophobic, racist, the cultural symbols embedded within our educational system, or the material conditions that are rooted in and continue to benefit WMCM, the oppressive trinity is ever-present physically or otherwise.

At this point the oppressive trinity is a self-perpetuating cycle; capitalism, racism, and patriarchy are embedded within the fabric of every institution and organization in our society informing our identities shaping how we perceive and navigate the world in such a way that we perpetuate it in our institutions and organizations. Those who are born without the prerequisites to exhibit the physical manifestation of the oppressive trinity are held to its standard. Those who are born with the "right" skin color, parents' income bracket, and chromosome are provided the identities and privileges that place them in positions of authority and power and knowingly or unknowingly perpetuate the system that benefits them.

\section{Personal Developmental Trajectory \& Autoethnography}

We often strive to understand how concepts work in our society however, there is a limitation in the tools we provide to recognize how these concepts manifest within our own lives and how we can work to utilize, maximize, or minimize them. The second half of this article is devoted to exploring praxes and practices I have used to recognize the oppressive trinity within myself, the research I conduct, and the educational strategies I employ. Within this section I take time to discuss critical self-reflexivity and positionality and the autoethnographic methodological style that can be used to move from a personal practice to academic engagement. I follow this with an autoethnographic account of my own history and how it has been shaped by the oppressive trinity.
Further, within this autoethnographic account I discuss more praxis and practices I have employed when exploring my identities and strategies when conducting research and / or educating.

Research on the self needs to be more than a decorative piece within academic engagement. It needs to move or persuade the reader to a space they would not have been able to go without the deep insight that a personal narrative provides. I hope my personal narrative in this text provides an introduction to praxes they otherwise may not have come across while also showing them how these praxes have helped me recognize the oppressive trinity within myself and how I strive to be cognizant of its presence when conducting research and / or educating. It is on us as researchers and educators to not only understand what the oppressive trinity is but be able to recognize it within our immediate. It is on those of us who possess the identities of the oppressive trinity to begin to interrogate how it has shaped who we are and begin to add these experiences to the literature in order to create a broad yet deep understanding of how the oppressive trinity operates within each of us while furthering our understanding of the oppressive trinity as an ideology that governs our whole society and how we (those who possess it) can be researchers and educators of change.

\subsection{Critical Self-reflexivity \& Positionality}

The critical self-reflexivity process I have engaged in, is what Kohan [42] implements within several of his classes, titled personal developmental trajectory. Kohan challenges his students to engage in a number of practices and exercises he has enveloped within his class for students to engage in deep and mindful meditation about an identity they possess. The exercises are meant to stimulate individual's thoughts on what one particular identity meant for them and why? What are the socio-political realities constituting this identity and why? How has the identity been present both overtly and covertly throughout an individual's life and why? This practice is partly rooted in Milner's[43] "framework for researcher racial and cultural positionality" in which Milner describes a number of steps researchers can take including, "researching the self, researching the self in relation to others, engaged reflection and representation, and shifting from self to system". Researching the self consists of asking a number of reflexive questions that ask an individual about their racial and cultural heritages and identities. Researching the self in relation to others pushes researchers to examine what they know about the people they are studying and challenge any understandings they may possess. Engaging in reflection and representation, according to Milner, is asking participants about their thoughts and truly listening to what they have to say. While as a researcher one may surmise a situation one way, the participants may interpret the same situation differently. This is an opportunity to explore different understandings and interpretations of the world adding diverse cultural depth to academic conversations and 
theoretical understandings. The final aspect of the framework is shifting from self to system, which entails understanding how "policy, institutional, systemic, and collective issues" affect an individual's racial and cultural system of knowing and navigating the world.

Kohan teaching future educators has adapted this framework and includes challenging his students to engage in these practices in their classrooms while also having them construct an exercise fellow practitioner can use as a tool for engaging others within their own personal developmental trajectory. Kohan does not only view this as a consciousness raising exercise rather a continuous project of self and educator as a fair, equitable, and socially just educator. The importance of this practice across all fields, including fields that research is conducted cannot be understated. We, as researchers, need to engage in practices that push us to understand who we are in relation to others and the oppressive trinity governing our society. Further, departments, organizations, companies, schools are different and unique to the field, business, member composition. Creating an exercise that is context specific for understanding and recognizing the oppressive trinity in an organization is not only a practice of exploration with the individual(s) who builds the exercise it also ensures the exercise is well tailored to those who are in the room.

Further emphasizing the need to engage in personal developmental trajectory practices is highlighted in the statistics I listed at the beginning of this text. The overwhelming majority of faculty members and educators in multiple educational environments continue to identify as white although American communities are increasingly becoming more racially and ethnically diverse. Further, at the current moment these discussions of self-reflexivity and positionality are not widely engaged in by sport practitioners (Athletic Director, Academic Advisors, Tutors, Mentors, Coaches, etc.) even though these practitioners are more likely to be working with individuals of diverse racial and cultural communities [44].

\subsection{From Self Practice to Academic Engagement}

Those who have engaged in athletic autoethnographic and critically reflexive pieces have focused on the fans voice [45, 46], athletic experiences [47, 48], and introducing autoethnographic approaches to sport management [49] Engaging in self-reflexive practices is important, however when transferring these practices from an internal practice to an external practice in academic literature there are a number of important aspects to consider. Autoethnography provides a strong methodological basis for conducting academically rigorous approaches to this type of work [49].

Steps within autoethnography include being aware of the purpose of inquiry when delving into this field. While I am highly encouraging everyone to engage in these praxis to become better educators at multiple levels, I have chosen to present my narrative in an autoethnographic style to highlight my identities, privileges, and experiences with the intention of unpacking larger socio-political theoretical implications. Engaging in autoethnography is not a space for autobiography. It needs to be a constant shift between personal experience and theory, critically analyzing one's feelings, emotions, and actions as they navigate the world. I liken this to a basketball player. They are not only required to play offense, but are also required to traverse the length of the entire court playing both defense and offense. Within autoethnography the individual needs to provide detailed accounts of their feelings, emotions, and actions while also connecting theoretical understandings and implications.

An appealing aspect of this methodological style of traversing in the experiential and theoretical is the disregard for anchoring to one theoretical approach. This is described as 'bricoleur' or the literal translation of quilting patches together [50]. Within the ethnographic tradition it is the patching of theories together as needed. This allows for greater depth as different experiences can be examined under different theoretical concepts, stretching theories to their limitations providing opportunity for theoretical growth. It allows for interdisciplinary analyses to occur as individual narratives provide rich data accompanied by theoretical approaches, which enhance the author's ability to truly unpack, understand, and further forms of knowledge and theory.

While relying on one's personal experience there is still a need to provide a broader discussion of political, cultural, and social contexts. Triangulating what one is feeling with experience and larger contexts provides the depth for which autoethnographers are striving to accomplish [51]. This provides a unique stylistic approach for presenting this literature. Often autoethnographies read as personal narratives interjected with theoretical and analytical conversations. There are concerns with the legitimacy of this methodological style, however Ellis et al. [52] provide support for autoethnographic validity and reliability. They describe validity and reliability within this method as, " "...verisimilitude; it evokes in readers a feeling that the experience described is lifelike, believable, and possible, a feeling that what has been represented could be true. The story is coherent. It connects readers to writers and provides continuity in their lives'. Reliability stems from the researcher as a primary and reliable source. It is up to the reader to determine whether they trust and believe the narrative presented to them. However, this is part of the autoethnographic methodological style; the goal to provoke emotional and critical response. What are the similarities of the autoethnographers story to that of the readers, where does the reader take issue and why? This as Spry [53] argues transforms the text from an individualistic text into a communal text.

In short the autoethnographic process consists of, 1) providing a purpose of inquiry; 2) providing detailed accounts of personal experiences while interrogating those experiences with theory; and finally 3 ) triangulating personal 
experiences with larger social, political, and historical contexts to provide further depth.

\section{The Oppressive Trinity within Me}

This text was inspired by the autoethnographic writing approach of Tim Wise's [54] White Like Me. I hope to weave and intertwine my experiences in a dialogue with oppressive trinity, my identities, and the privileges attached to those identities as they are constructed in myself and in society. I will then discuss my introduction to Peggy McIntosh's notion of unpacking the invisible knapsack, Paulo Freire's notion of need based education, and finally Critical Race Theory's and Critical Latino/a Theory's of alternative epistemologies. Almost every day of the week I am working with individuals who possess a racial identity and class identity vastly different than mine. As I have engaged in these praxes I have become aware of how the oppressive trinity has manifested itself within the research and educational methodologies I have engaged in. I hope my narrative will provide a template for others to engage in these praxes for those who strive to become better youth program developers / leaders, researchers, mentors, and educators.

\subsection{Raised as the Norm}

Within, White Like Me Tim Wise provides a detailed history of his family background dating as far back as his first ancestors traveling to America. Unfortunately, within this piece I will not be doing the same; however I will take the time to discuss my first neighborhood, Lynnmour West. This neighborhood is a series of roughly 200 town homes all connected within a hundred square kilometer area, located just out of the way of a major thoroughfare connecting Ironworkers Memorial bridge to downtown Vancouver and various communities of North Vancouver, British Columbia, Canada. My home at 1234 Premiere Street was not the first house I lived in, but it was my first home. It is where I lived until I was 11 and continued to frequent even a few years after I moved away. It was in this community I began to exercise in racial narratives, try-out and put on masculine ideals, while being surrounded by other families that were composed of two young professionals. Almost everyone in the neighborhood had children as it was generally each family's first home they were able to purchase.

Premiere Street was a child's paradise. As young as six I was letting myself out in the morning and not coming home until what felt like midnight. With the whole community being comprised of young families no matter what time of year the streets, designed only for emergency vehicles and therefore always clear of cars, were filled with children playing. Just down the hill from the complex, as the neighborhood was colloquially known, was a large outdoor lacrosse box where we could be seen and summoned by our parents when needed. There were large green spaces, a community pool, a playground, forested area bordering the backside, a river a twenty minute walk away, replete with trails craving through the forest and as I grew older, the dump a little ways behind the community was turned into several large baseball and soccer fields.

To this day I still cherish that neighborhood. Growing up and being able to spend long days riding bikes, playing hockey, getting involved in all kinds of mischief. I liken it to a neighborhood Disney would construct for one of its fantastical movies. Interestingly, it has taken moving across a continent to a new country for me to reflect on that space critically. Lynnmour West was built throughout the 1970s to service the growing population of the greater metropolitan area of Vancouver. While Canadian cities managed to stave off the mass exodus U.S. cities experienced, there were still many families who chose to live just beyond Vancouver proper's boundaries and make the short commute into the city center.

The neighborhood itself was etched out of forested land that was becoming industrialized. There was a working dump behind the community and a working shipyard that moves grain, sulfur, timber, and coal still exists a short drive away. The neighborhood is also buttressed by the Tsleil-Waututh nation and the Squamish nation (which is actually an amalgamation of sixteen native tribes that originally inhabited the area) reserves; parcels of land the Canadian and other local governments sanctioned First Nations people to inhabit. It was on this unceded territory that Lynnmour West was built and my parents purchased their first home.

While individuals from the Tsleil-Waututh and Squamish nations were still handling the effects of residential schools, a form of apartheid, generational genocide, and the destruction of their homes, lands, and spiritual spaces $[55,56]$ me and my family were able to acquire a mortgage with relative ease and the recognition of potential wealth accumulation to move into a quaint neighborhood. As I am a product of my family, they too are white and so were about $99 \%$ of the families that lived in the neighborhood while I was growing up. While Feagin discusses the unjust enrichment of white folk and unjust impoverishment of Black people within America, the basic theoretical tenet can be applied to the construction of who I am. While I did not directly repress First Nation populations to secure the land in which my first home was built our profiting from clearing of that space for the purposes of providing homes to white families makes us complicit within the larger racial structure creating inequalities throughout Canadian society. Canada is founded on the systematic removal of First Nation populations from their land, and the purposeful segregation of them from larger community, town, and city life. It is founded on the forced education of First Nation populations. It is founded on the racialized language used to demonize, deport, and ban Chinese immigrants for being successful in business ventures. It is founded on the countless number of refugees we have turned back to their home country to be 
slaughtered. It is founded on immigration policies that have been designed to ensure the immigrants who stay in Canada resemble Canadian heritage while those who do not are exploited at minimum wage and are sent back to their homes due to "complications" with their status. While Canada does not have the same racial issues of America, it is not free of a racially oppressive system.

Each of these injustices can be couched not just within capitalism, racism, or patriarchy but rather the oppressive trinity. Each of these populations did not fulfill the requirements to meet the standard imposed by white, middle to upper class men. They were different and if, the First Nations populations were to be a part of Canadian society, they were going to be educated in "Canadian" values and standards; read oppressive trinity standards. This resulted in the destruction of families and individuals from the $19^{\text {th }}$ century to as late as 1996 as children were forcibly removed from their families and communities to attend residential schools. This not only resulted in a loss of culture but also an unprecedented amount of abuse and death. These schools were created to submerge First Nation populations in the oppressive trinity. These schools were not designed to just teach capitalist ideals, or hegemonic masculine values, or proper English manners. These schools were to strip the people of these Nations of their identity and rebuild them in the image of the white, middle class, male. For instance, children were barred from wearing their culture's clothing and were forced to wear and appear like middle class, urban teenagers [57]. Clothing acts as a cultural symbol through which individuals express who they are not only as a fashion statement but also as a cultural expression or homage. It cannot be clearer that the goal of these schools were to educate First Nation individuals in the oppressive trinity. This meant the weakening of First Nation populations and culture allowing for continued colonization throughout Canada. It resulted in allowing colonizers to almost unimpededly ravage the West Coast through logging, which opened the corridor for what would become my neighborhood.

Nonetheless, this paper is not geared towards discussing Canada, rather it is to highlight how this system has informed my identities. It is important I recognize these racial and economic systems as they constructed the space I came to be constructed in. Even if my parents somehow existed within a vacuum who did not benefit from the generational wealth and opportunity afforded to them by their parents, the generational wealth and opportunity created by a system that segregates and relegates First Nation populations to particular lands while allowing white populations to flourish where they please shows how I have benefited from systems designed to economically advantage a particular group while continuing to disadvantage different groups. This is the material manifestation of the oppressive trinity within Canadian society. It demonstrates how even in the physical absence of a white, middle class, male body like my own, the systemic oppression is maintained through these material manifestations. I was given a safe white space where I could run around with other white children and have the idyllic childhood experience while the First Nations neighborhoods buttressing mine were stigmatized and characterized as the places we do not travel through for any reason.

Growing up in this material manifestation of the oppressive trinity also allowed me to be bathed in social practices of capitalist, racist, and patriarchal norms of our society without even being aware. This is Feagin's white racial frame; the notion that white individuals understand and see the world through their fictionalized history, knowledge, and understanding without seeing the oppressive system governing society. This fictionalized history, knowledge and understanding has and is normalizing narratives of conquest, of ways of thinking and problem solving, of consumption and interaction with the Earth. It normalizes what occurs within the private sphere of households like forms of media consumed, language used, punishments performed and draws them across the entire society as the standard. This neighborhood was designed for the express purpose of helping families exhibit the normative standards of our society while excluding those deemed as "Other".

It was not until I removed myself from my community entirely was I able to fully comprehend how much the three doctrines overtly and covertly operated, just within the construction of that neighborhood. This construction was intentional to ensure I, along with my neighbors, came to embody the oppressive trinity and work to maintain it as our society's normative standard. The Lynnmour West neighborhood fed the hard working, meritocratic, entitlement narrative integral to maintaining the WMCM identities through which the doctrines of capitalism, racism, and patriarchy physically manifest. The families who lived there were first time homebuyers, young professionals, and for the most part parents to several children. They worked hard to achieve and maintain the desired lifestyle. However, their hard work was bolstered by a racist and patriarchal economic system that actively disenfranchised any individuals who did not fit into the desired identities.

\subsection{Exercising the Norm}

Within my own story I cannot separate my identities of white, middle class, and male nor can we escape the reality that that is the norm across North American society. The Lynnmour West community was cleared and carved out primarily for white families to maintain their ascent towards the oppressive trinity. This is in stark contrast to First Nation populations being historically restricted to reservations and Black and African Americans having their communities "redlined" limiting economic growth for both groups. The system operates to ensure economic opportunity for white people at the cost of specific racial and cultural groups.

This cost in American society is apparent when examining the racial disparities among policing, charging, and 
sentencing $[58,59]$, educational disciplinary actions [60] and adverse health outcomes [61] and even in athletic participation [62]. Freiburger and Hilinski [63] discuss how men who identify as Black or African American are more likely to receive higher sentences compared to individuals who identify as white committing the same crimes. As Feagin discusses systemic racism places many burdens on the Black and African American communities, which has resulted in financial hardship among many others (e.g., mortality rates, destruction of family units, etc.).

Lynnmour West was created to help families strive to meet the idolized white middle class unit of fathers heading to work while mothers worked the double day. It is reflected in the fact that my parents were so willing to allow me to leave early in the morning and not return until late at night. It was spending much of that time at the lacrosse box, playing hockey with the boys and if it was not hockey it was playing with BB-guns, throwing water balloons into peoples' cars, stealing signs, and acting with little regard for others all the while not having to worry about facing any dire consequences such as being stopped by the police or even being arrested or killed like Tamir Rice or Michael Brown.

As I grew older it was drinking, partying, invoking the five-fingered discount at my place of employment, and even getting picked up by the police for being drunk in public at the age of 15. I was able to engage in all of these activities, like the majority of my friends and peers around me without having to worry about real and severe consequences. Even when the police picked me up, I was dropped off at my parents' home with a warning. The countless times my friends and I were caught doing something we should not have been doing it was a slap on the wrist, a punishment prefaced with, "now I know when I was young I did similar things but...". The common 'boys will be boys' sentiment normalizes our behavior as part of the growing process. The unfortunate reality is, as the literature above shows, individuals of diverse racial and cultural communities are not afforded the same leniency and securities as me when caught doing the same things.

The 'boys will be boys' sentiment should read, 'white boys will be white boys' as Johnson and Johnson[64] describe how poor, non-traditionally educated, morally reputable, and anti-social behavior is something that exists across all groups of individuals, but is disparately labeled on black male bodies. There is an assumption of innocence of white boys wrapped up within the 'boys will be boys' narrative. Although, I was caught doing something wrong it was part of the maturation process, something that could be excused due to my white masculinity. Compared to those who identify as Black, African American, or Latino boys the same leniency is not provided. This allows white boys to continue on a trajectory towards middle class or even upper class comfort while disenfranchising and oppressing young men of diverse racial and cultural communities the opportunity. It allows me, a white middle class male to continue to live my life undisrupted as I only made a "few mistakes". In contrast Black, African American, and Latino boys are more likely to be sentenced to jail before they even turn 18 years old removing them from the education system and hindering their ability to engage in economic opportunities that were afforded me.

The systemic nature of the oppressive trinity, not just race, creates a society that allowed me to engage and really encourage my involvement within these risky social practices. I not only was afforded the innocence of childhood through to the university due to my whiteness, but I was also provided freedoms that praises and glorifies these activities. Being a part of the party culture and all that came with it through my teenage years was a source of pride. However, I never had to worry about my safety when I over drank as young women do (i.e., Brock Turner case at Stanford University). Nor did / do I have to worry about my sexual activity being labeled as slutty, hypersexual, or as a hyper-aggressive act. I was able to engage in the party culture during my teen years, have my parents, several other parents, and my teachers be aware of it and yet still receive and rely on their support as I matriculated into university and subsequently graduate school.

Despite all of the drinking, partying, stealing, vandalism, and general disregard for rules and authority, I was able to get into the University of British Columbia, find employment, and be rewarded for my temperament and work ethic. My embodiment of the oppressive trinity through my physical embodiment was further constructed being raised in a space that encouraged social practices that reinforced ideological fallacies such as meritocracy and boys will be boys. I have been able to continue to maintain my middle class comfort and pursue a highly respected career. The oppressive trinity of capitalism, racism, and patriarchy constructed Lynnmour West as a material space to ensure the continued enrichment of white people in society while also shaping those who lived and were raised within that community to be blinded to the realities allowing for that enrichment to take place. The 'boys will be boys' narrative, the reinforcement of meritocratic ideals, the glorification of risky behavior, and the praise of sexual conquests were all operating at the systemic level through institutions and organizations, through material and symbolic manifestations within our society, and came to be internalized in my identities such that I embody those narratives in how I perceive, understand, and navigate the world.

\subsection{Using the Norm}

I place a great deal of credit for where I am today on a few teachers who saw potential in me. Those teachers inspired me to become a high school history teacher. Although, I never took a history class until my last year at the university and never became a high school teacher, those teachers inspired me to seriously consider the next educational level. It was in that educational setting I was introduced to sociology as a subject matter, but also introduced to theories 
of oppression, exploitation, and racial discrimination. It was within that space I was able to become aware of the systemic oppressions that exist in North American society.

However, it was not until moving across the continent to a new country was I encouraged and began to think about my positionality within these oppressive systems. It was at this time I was introduced to Peggy McIntosh's exercise of unpacking white privilege, Freire's notion of relationship building in education, and Latino/a Critical Theory's and Critical Race Theory's alternative epistemologies. This is when I was introduced to self-reflexivity, autoethnography, and personal developmental trajectories. Engaging in these practices and theoretical praxis has been transformative in how I understand and navigate the world.

As I mentioned at the beginning of this text, I currently possess a number of roles. This includes being an academic mentor for the most academically underprepared student-athletes. Within this role my responsibilities are to be aware of the student-athletes' course responsibilities (assignments and exams) with the intent of aiding the students with organizing a schedule for completing everything down to organizing the structure of an assignment and making sure they complete tasks on time. Essentially creating detailed task lists with the students and holding them accountability for completing their work. When needed, I am also a tutor for them in subjects from drama to pharmaceutical science. These are long nightly sessions with the intent of providing support to those who take longer to complete assignments due to learning disabilities to individuals who have not been given formal education on essay structure to individuals who struggle with time management as they transition from high school to university while also being a student-athlete.

I am also a program leader for a community-campus partnership organization that has partnered with several community organizations located in a specific community in a local metropolitan neighborhood. Within this program I am a program leader for a boys leadership program for seventh and eighth graders at one of the pre-K to eighth grade schools in nearby metropolitan city. The program conducts participatory action research (PAR) with the young men we work with specifically focusing on developing leadership skills within the young men through various activities such as physical education, team building, and critical thinking workshops. I also work with a community organization that provides a communal house for local kids to play, complete schoolwork, and engage with positive peers and adults within the same neighborhood.

I am a graduate assistant for the sport management program at my university. I help my faculty advisor conduct research on athlete activism while also acting as a teaching assistant for an Introduction to Sport Management course. I am also part of a PAR project for holistic development support group for college students including athletes designed to provide members with the tools necessary to excel in life beyond sport.
I have been able to obtain each one of these roles because I was excused from my previous mistakes, which allowed and inspired me to become a teacher. Based on the unearned privileges associated with my identity, I was able to attend the same school throughout elementary school, and high school, because I grew up with parents who were willing to drive me to a "good school", because we were able to purchase a home in a "good" neighborhood. Although, I moved across a continent to a new country I was still able to leverage the privileges my identities possessed not just through my possession of them, but through the accumulation of privileges afforded to me.

Wanting to be a high school teacher I knew it was going to be important for me to gain classroom experience. At the age of 15 I was going back to my old elementary school, which was one block away from my high school, and volunteering for my $6^{\text {th }}$ grade teacher as an assistant. This role involved assisting with teaching tasks and working one-on-one with students who needed extra attention. I maintained this role through my first year of university.

After falling away from doing any extra-curricular work for a while in my third year of university I was introduced to a program working with Bhutanese refugees. I was placed in a tutor role working with high school boys on English second language skills. This eventually turned into helping coach the program's boys' soccer team. I was also able to use this program for an ethnographic research study. It was there I began to find a passion for research, pursue an undergraduate research project, and utilize the success of my undergraduate research project along with my volunteer work to propel myself into graduate school.

However, this all hinges on the reality that my actions throughout my childhood and teenage years were not criminalized, but rather normalized and accepted. Despite being in several fights in elementary school and only receiving one in-school suspension for throwing a snowball. Despite being caught vandalizing property several times and never being brought in front of authorities or even my parents. Despite having several encounters with police and being apprehended for being drunk in public and still being able to go back to my old elementary school, welcomed, and given a volunteer position that I was able to use to help get into university. I benefitted from a system that viewed my identity as the standard for humanity and success.

While Feagin and others may attribute this all to racism, with class and gender playing pivotal roles here and there, the reality is my race, class, and gender helped shape how I was treated and the opportunities I was provided. I was not afforded these opportunities just because I was white and the system is racist, but rather it was the fact my family could afford my mother working part time so she could be there to pick me and my brother up after school and drive us home allowing the teachers to get to know my parents. It was the fact that it was my mum picking me up from school right after she finished work, helping me with my homework, and then preparing dinner so my dad could continue to work all 
day. The system is not just racist, but rather is designed to benefit white middle class males and the system will continue to as long as it is informed by the oppressive trinity and will continue to be informed unless we begin to recognize how it is operating / governing each of us through critically self-reflexive practices.

\section{Recognizing the Oppressive Trinity}

At the beginning of my graduate work I was challenged to recognize my positionality within the oppressive structures. The insidious nature of the oppressive trinity constituting White culture and the social practices, cultural symbols, and material objects that exact this culture as the normative standard across the entire society is the veil that blinds us, White middle class males, to the oppressive trinity and its operation in every facet of life. Du Bois' use of the veil for African Americans is apt for explaining a similar disillusionment of self-consciousness we, as White middle class males experience. While not a seamless appropriation, physically embodying the oppressive trinity in my identities and being bathed in the social practices, material objects, and cultural symbols that normalize everything I do, makes it extremely difficult to even recognize how the operation of these doctrines disproportionately affects individuals who do not possess the identities of the oppressive trinity. The social practices, material manifestations, and cultural symbols permeate our society, which does not allow us to see our true self-consciousness within the larger institutions and structures of society.

When I went back to my elementary school to volunteer as a teacher's assistant and when I coached rugby for my high school's Grade Eight team, the veil kept me from acknowledging and challenging these norms as the standard. Engaging in the same narrative that was fed to me as a young, white middle class male with the young individuals I worked with, I did not encourage, but I also did not discourage the same behavior I engaged in at their age. I often used my experience as a testament to how we could make mistakes and still through hard work succeed in school and life. When I worked with Bhutanese refugees I would talk with them about working hard, but also going out and have fun totally unaware of the vast differences in the micro politics governing their neighborhood compared to mine.

Although the veil created by the oppressive trinity kept me from being aware of the vast differences between my experience and the experience of the young Bhutanese refugees I worked with, gave me the opportunity to engage with a culture that was vastly different from mine. This created the first rips within the veil that has allowed me to shred the veil more thoroughly as I have been introduced to praxes that forced me to critically assess my work with the refugees and as I began to work with populations very different from my own. Most importantly it has allowed me to recognize the continued advantages I receive do to my possession of the oppressive trinity in my day-to-day.

Part of the process of recognizing the oppressive trinity within myself has been understood the privileges that each of my identities afford me. When I was introduced to McIntosh's [67], "White Privilege; Unpacking the Invisible Knapsack" it changed my world. Obtaining my undergraduate degree in sociology I was aware of the systems of oppression that existed throughout our society; however, I had never been challenged to place myself within the system. I had never been challenged to recognize how my physical embodiment, material reality, social practices, and cultural symbols I subscribe to in my immediate reality directly connected me to oppression. McIntosh listing the privileges she experienced on a day-to-day basis as she experienced them resonated with me. I could instantly see several privileges my skin color was affording me. I began to make lists in same fashion as she describes and eventually started to replace white with male, and then with middle class, and then heterosexual and so on. At this point my list feels endless, but this is my reality and being aware of these circumstances and related systems that provide an individual with the identities I possess with an abundance of privilege is crucially important.

Making these lists of privileges is hugely beneficial to recognizing how identities provide privileges. Considering there are identity compilations that provide some privileges but not the full amount of privileges that the oppressive trinity does, connecting one's identity compilation to the oppressive trinity is a necessary step. Within the personal narrative I have given above I delve into my personal history, focusing primarily on the neighborhood I was raised in. For me, this neighborhood was a significant aspect of my life. I recognized this even before I began engaging in this work. For others who decide to inquire about themselves and how their identities exist and are shaped in relation to the oppressive trinity choosing an aspect of one's life that is significant is a strong place to begin the exploration. This could be anything from one's neighborhood to a sport they play or the major they chose to pursue during their undergraduate work. This awareness allows us to recognize how the oppressive trinity manifests itself in the individual through institutions, structures, and organizations that create, maintain, and disseminate material realities, cultural symbols, and social practices that perpetuate the oppressive trinity as the normative standard. While groups of individuals who possess the same identities may have similar experiences the route they choose to explore their identities provides contextual, temporal, experiential investigations of the oppressive trinity in operation.

Recognizing and interrogating my identities and the privileges attached to those identities is the first step to engaging in emancipatory strategies for disrupting the oppressive trinity's effectiveness in society. We need to know how they manifest within ourselves as well as in relation to the oppressive trinity as a governing ideology in our society. Moving towards recognizing the oppressive 
trinity in the research and educational practices I engage in is difficult. I can recognize my privileges, however this has not translated into an ability to recognize that not every individual holds the same privileges and even if recognizing this reality, adequately changing my strategies of engagement. We can turn back to Milner as he provides a number of questions structured to determine the self in relation to others. Again, Milner wrote these questions in relation to being a researcher working with individuals possessing different identities than their own.

These questions include, "What are the cultural and racial heritage and the historical landscape of the participants in the study? How do I know? In what ways do my research participants' racial and cultural backgrounds influence how they experience the world? How do I know? What do my participants believe about race and culture in society and education, and how do they and I attend to the tensions inherent in my and their convictions and beliefs about race and culture in the research process? Why? How do I know?" as well as several more. These questions are geared towards researchers working with individuals of different racial identities in an educational setting. However, if we expand these questions to include any field and with the oppressive trinity in mind we are able to transform them from this specificity to a broader conversation of the oppressive trinity as a governing ideology. For instance, if we take the question, "In what ways do my research participants' racial and cultural backgrounds influence how they experience the world? How do I know?" and change it to "In what ways do my research participants' identities experience the world in relation to the oppressive trinity? How do I know?" allows us to expand the conversation way from a myopic fixation on one identity and begin to engage in more complex understandings of how the oppressive trinity operates when governing others' lives. Further, we can begin to understand how one understands the oppressive trinity operating within their life and compare it to how another sees it operating in theirs. Again, this adds the complexity and nuance into the research as well as the educational strategies.

That complexity and nuance however is predicated on participant voices being recognized and included within the exploration. Freire [68] takes a significant effort to discuss his concept of banking education. This is described as the depositing of information into the empty vessel of the child who then needs to memorize this information in order to be deemed normal and successful in the eyes of the teacher and the oppressive system. For Freire exercising this approach to education indoctrinates students and shapes them to conform to an oppressive understanding of the world. Part of this educational indoctrination is the teacher-student relationship. The teacher is a narrator of knowledge, an individual who possesses the knowledge and who judges others competence of the knowledge. The student is an empty vessel, an individual who does not possess knowledge and who must engage in rote memory to be judged as successful. This approach to education detaches individuals from who they are, their communities, and places them onto a conveyor belt to be assembled in a fashion to meet the needs of the oppressive group.

While Freire maintains a fairly broad definition of what the oppressive ideology of a society is, within North American society the oppressive trinity governs every aspect of our society. Further, part of the issue here in North America is a significant portion of those in research positions and educator roles across multiple levels are white and have been raised in a society which values their ability to meet the oppressive trinity's normative standard. However, critiquing the teacher-student dichotomy and choosing to approach the relationship differently provides the opportunity to move from an indoctrination process to one that is humanizing and co-constructive.

I have been a researcher and an educator in a variety of capacities and have acted as a narrator who possesses the knowledge that "beams down on to the heads" of my students for them to absorb and recite or constructs a narrative about my data collected without consulting those I have observed and interviewed. This process is the way I was raised through education. It works for me not because "my brain works that way," but because I embody the ideological doctrines that are engrained within the educational message beamed down. As our society is becoming more diverse and there are a disproportionate number of educators who, like myself, possess the oppressive trinity, changing how we view ourselves in the teacher-student / researcher-researched relationship is vital. Aware of the dichotomy inherent in the title of these roles I now try to spend as much time as I can to build a relationship with my students, advisees, and mentees. This is one of the most crucial components towards a transformation as an educator and researcher. It consists of negating the titles placed on us by structural forces such as an institution of higher education or an athletic department and acting as an individual with a genuine interest in understanding those we engage and interact with in these roles.

The questions listed above as well as the many others Milner provides are strong starting points, but nothing works as well as engaging in dialogue with those we serve. Who are they? What do they want to accomplish in their life? What is it they need? What are their strengths and weaknesses? How are they an asset within this relationship the classroom or team, their family, community? What type of music they like or who their favorite athlete is? Where have they traveled? These are all questions that rarely have anything to do with the material they should be learning, but has everything to do with establishing a relationship beyond the teacher-student title. It shows that as an educator whether being a mentor or a teacher as an individual we have a sense of holistic care for those we serve. From a researcher stance, taking the time to thoroughly explain the project, questions, who I am as researcher are important in addition to building a rapport with the research participants over several meetings has benefits. It allows the participants to shift from research 
subjects to human beings and even having them move toward research collaborators. Through extensive conversations it is likely they will suggest topics and connections the researcher has never recognized, observed, noticed, or thought of before. Engaging in the conversations, expanded to explore the oppressive trinity, provided by Milner allows a rapport to be built. It establishes a sense of credibility and importance within the individuals participating.

As an employee with an athletic department I am bound by a confidentiality agreement and contractual obligations and therefore limited in my ability to discuss my mentoring relationships and even limited in my ability to pursue Institutional Review Board (IRB) approval. However, I am able to provide my personal perspective on how I see the implementation of these strategies unfolding. Approaching many of the relationships by disregarding the titles and taking the time to learn about who the individuals I work with are, how they are doing on a daily basis in all aspects of their life has allowed us to build mutual trusting relationships. Hooks describes this work not as critical pedagogy but rather engaged pedagogy. There needs to be an emphasis placed on our own well-being, as educators, as well as the well-being of the individuals we are educating. Our approaches to education, even within an athletic department are to compartmentalize everything. We are not to discuss their sport with them or private life. We are there to educate them on the subjects they are taking. I have come to see this as impossible as I generally meet with the athletes I work with at night, after they have endured weight training, classes, athletic meetings, and practice. Their athletic identity cannot help but creep into our interactions. Further, most of the individuals are young men going through university. They are not immune to social realities that constitute university experiences. Taking the time to engage with each of them on a humanistic level has paid dividends. Hooks stresses the need for us as educators to give some of ourselves in order to help facilitate the growth process but also to show the students we as the educator are invested in the students. At these moments when discussions of relationships, family life, emotional distress, physical exhaustion compartmentalizing cannot happen. Providing my own experiences that reflect those they are experiencing has led to a growth in our relationships.

I feel engaging in these strategies has benefited my work greatly as many of those I work with reach out consistently out of mutual respect and a desire to stay connected. It has translated into encouraging some of those I work with to attend an organization designed to facilitate the holistic development of Black student-athletes. However, most importantly to me it has resulted in open and honest conversations about what is happening within my and their personal lives, academic lives, and athletic lives so we are able to work together to facilitate all of our goals.

The importance of this relationship building process is even more important as many of those I work with possess very different identities. I work with predominantly young
African American males from economically disadvantaged areas and me, a white male from a middle class family from Canada. I can never know what life was and is like for those I work with, but taking an active interest in their life has allowed us to have conversations about our respective backgrounds. It has allowed us to talk about where I am from, how it is different and similar and begin to widen the horizons for the both of us in recognizing how the oppressive trinity operates within and in relation to ourselves. This text has been inspired by those conversations in which we engaged in complex, deep, but honest conversations regarding personal experience. There are some [69] who have argued there are barriers to conducting research especially based on socially constructed racial differences. Having a conversation with anyone about a complex and charged issue within this country is always difficult. However, with the individuals I work with, I have had very candid conversations regarding race and how we view racial issues differently throughout our society. These conversations did not occur the first time we met or after a month of meeting together. However, after several months of meeting and getting to know each other, experiencing some failures and some successes together we have come to a place where these types of conversations are common and open.

I understand that not every researcher has months to make these types of connections due to research limitations and pressures. However, research should be developed to provoke thought, spur understanding, share successful and unsuccessful experiences, and / or motivate readers to engage in or construct their own programs, practices, and understandings. Conducting intentional relationship building provides opportunity to better capture the experiences and knowledge of those we serve and work alongside. Capturing and including their voices in our research creates opportunities to elevate their voice from that of the margins of society to being part of the whole and centered. Designing research projects to be longitudinal with multiple iterations of data collection, analysis, and presentation should be considered for all research projects.

As researchers and educators we too have the ability to hear the voices of those we are working alongside and serving. Taking the time to learn who the people we are working with, holistically provides us with an opportunity to tailor our lessons to make them more appealing. Further, working with a number of young men in the athletic department has shown me what many critical race theorists and Critical Latino/a theorist have been arguing for years, which is the importance of acknowledging the alternative epistemologies individuals possess throughout our society. Bernal [70] discusses the importance of recognizing alternative epistemologies in educational practices.

Currently, the dominant epistemology our society favors is the oppressive trinity experience and way of knowing. From standardized testing to the stories we create and recreate through the cultural symbols of our society such as mass 
media, political parties, etc. It is in the history we teach in the Kindergarten through grade 12 public education systems to how the justice system perceives, understands, and adjudicates decisions. Bernal highlights how students in her study believed themselves to be advantaged due to their bilingualism, biculturalism, and their commitment to their community. They were not only assets to their community, but became assets to their schools as well as helping to bridge divides between community and school. Valuing alternative epistemologies is important for a number of reasons. It allows for students to understand diversity in problem solving. There are multiple ways to solve problems that are no less efficient and effective. Further, these alternative epistemologies empower students from diverse racial and cultural backgrounds and can enhance the relationship building process in educational settings.

Within the boys leadership program, where I am a program leader, in a local metropolitan community that is $100 \%$ Black, African-American, and Latino/a myself and 3 other male graduate students work with young men who are in the seventh and eighth grades. This program began with several months of meeting with teachers and administration to build relationships and then discuss best practices. It began with several months of building relationships with the young men in their respective classes. We have striven to include the voices of every stakeholder within the community extensively in the development of the program. In addition to having two meetings a week with the teachers to discuss the program and the development of the young men, every time we meet with the young men we take time to discuss expectations, forms of discipline, accountability, what it means to be a leader, the meaning of being a teammate. These are discussions where we, the adults, ask the young men to tell us what these things are, how they look in practice, and how we can facilitate a program so it resembles what they have expressed. Thus far, this program has allowed us to build strong "buy-in" from the young men, their teachers, and administration at the school. It has meant that the young men expressing a standard they believe they should be held to both in the classroom and the program. This is just one example as researchers and educators of the opportunities available to elevate our students' voices into the larger discourses that govern our relationships with students, the classroom, schools, and our society. By doing this we are able to investigate how the oppressive trinity operates in relation others and ourselves. Further, it disrupts the normative standard of the oppressive trinity while empowering our students from diverse racial, ethnic, and cultural backgrounds.

\section{Conclusions}

It has been the goal of this text to motivate and encourage current and future fellow educators, program leaders, mentors, coaches, and researchers to consider several practices to recognize how the oppressive trinity is within themselves and /or governs who they are. I presented here a number of praxes that can be used to foster meditation on how the oppressive trinity is embodied within us and the social practices, material objects, and cultural symbols we bring with us into educational settings. These praxes provide us with a small number of tools and practices to move towards being socially just and liberating researchers and educators. Through my engagement with these practices and praxes I have become aware of how the oppressive trinity exists within myself, how it operates systemically throughout our society, and have begun to consciously disrupt how it flows through me via the social practices I engage in, material objects I possess, and the cultural symbols I use. However, it is important to recognize that no matter how many practices, exercises, texts I write I will never escape the privileges afforded me through my embodiment of the oppressive trinity until this ideological structure governing our society is systematically changed or entirely replaced with an equitable and just system.

McIntosh [71] conceptualizes this as a bank account. This bank account of privilege no matter what I do will be filled with privilege every morning when I awake. This work is constant but greatly needed. Pursuing critically self-reflexive practices on a personal level and utilizing the autoethnographic as well as other alternative methodological inquiry styles to make these personal reflections public is crucial to replacing our current system. Individuals who embody the oppressive trinity and especially individuals who possess it in positions of authority to begin doing the work that will move them from understanding to recognizing the oppressive trinity within themselves, the organizations they are a part of, and how it operates as at the ideological level.

Throughout our society the oppressive trinity exists. It exists in physical embodiment, material objects, cultural symbols, and social practices. Unless we are to engage in revolutionary counter actions to dismantle this system then the system will persist. Thus, we need to act intentionally and effectively within and outside of the system to disrupt, challenge, and eventually change it. As a researcher, educator and an individual who embodies the oppressive trinity, this process is long and often very difficult as I am forced to acknowledge several discomforting truths about my family, my reality, our society, and myself. However, if I want to be an agent of social justice and liberator from the oppressive trinity as the normative standard, engaging in this personal developmental trajectory and self-work is not only important, but also imperative. I implore anyone who views their self similarly to do the same. I hope this text has provided a foundation on which to start the exploration of how the oppressive trinity resides within their self and in relation to them and others. This work is difficult however, I hope that the tools I have provided in addition to my experience will be beneficial to others wishing to recognize and explore the oppressive trinity within themselves. 


\section{Acknowledgements}

Thank you to the young men and women I work alongside side and serve in my university's athletic department and middle school where I am a program leader. They have and continue to teach me the most. Thank you to Dr. Joseph Cooper, my mentor, who challenges, but provides me the support to continue to do this work. Finally, thank you to the Sport Management program at the University of Connecticut for providing me with ample opportunities to engage in this work and giving me the knowledge to engage in this work.

\section{REFERENCES}

[1] J. King Jr., A. McIntosh, J. Bell-Ellwanger, The State of Racial diversety in Educator Workforce. U.S. Department of Education, Washington, D.C., 2016.

[2] Online Available from: https://nces.ed.gov/fastfacts/display.a sp?id=61, Fast Facts; Race/ethnicity of college faculty.

[3] R. Lapchick, J. Fox, A. Guiao, M. Simpson, The 2014 Racial and Gender Report Card: College Sport. The Institute for Diversity and Ethics in Sports, Orlando, 2015.

[4] S. Hall, Race, The floating Signifier, Media Education Foundation, Northampton, MA, 1997.

[5] M. Kohan, Personal Communication via email; PDT assignment, 2016.

[6] Online Available from http://www.oir.uconn.edu/Fall2016_E nrollment_Summaries.pdf

[7] Online Available from https://nces.ed.gov/pubs2010/2010015 /tables/table_24_1.asp

[8] K. Crenshaw, Demarginalizing the Intersection of Race and Sex: A Black Feminist Critique of Antidiscrimination Doctrine, Feminist Theory and Antiracist Politics, University of Chicago Legal Forum, Vol. 1989, No. 1, 139-167, 1989.

[9] S. Cho, K. Crenshaw, L. McCall, Toward a Field of Intersectionality Studies: Theory Applications, and Praxis, Signs; Journal of Women in Culture and Society, Vol. 38, No. 4, 785-810, 2013.

[10] K. Crenshaw, Demarginalizing the Intersection of Race and Sex: A Black Feminist Critique of Antidiscrimination Doctrine, Feminist Theory and Antiracist Politics, University of Chicago Legal Forum, Vol. 1989, No. 1, 139-167, 1989.

[11] J. Feagin, Systemic racism: A theory of oppression, Routledge, America, 2013.

[12] J. N. Singer, A. Weems, and J. R. Garner, Fraternal twins: Critical race theory and systemic racism theory as analytic and activist tools for college sport reform, Black Athletic Sporting Experiences in the United States, Palgrave-Macmillan, Houston, 11-55, In Press.

[13] M. Alexander, The new Jim Crow: Mass incarceration in the age of colorblindness. The New Press, New York, 2012.

[14] B. Hawkins, The new plantation: Black athletes, college sports, and predominantly white NCAA institutions. Palgrave-Macmillan, New York, 2010.

[15] J. Feagin, System racism, Systemic Racism: A theory of oppression, Routledge, America, 25, 2013.

[16] D. Solorzano, M. Ceja, T. Yosso, Critical race theory, racial microaggressions, and campus racial climate: The experiences of African American college students, Journal of Negro Education, Vol. 69, No. 1/2, 60-73, 2000.

[17] T. Coates, The case for reparations, The Atlantic, 2014.

[18] Online Available from http://connecticuthistory.org/the-effect s-of-redlining-on-the-hartford-metropolitan-region/

[19] K. Brown, Vile rogues and honorable men; Nathaniel Bacon and the dilemma of colonial masculinity, Good Wives, Nasty Wenches, and Anxious Patriarchs: Gender, Race, and Power in Colonial Virginia, University of North Carolina Press, Chapel Hill, 137-186, 1996.

[20] T. Coates, The case for reparations, The Atlantic, 2014.

[21] Online Available from http://connecticuthistory.org/the-effect s-of-redlining-on-the-hartford-metropolitan-region/

[22] A. Gegory, C. Hafen, E. Ruzek, A. Y. Mikami, J. Allen, R. C. Pianta, Closing the Racial Discipline Gap in Classrooms by Changing Teacher Practice, School Psychology Review, Vol. 45, No. 2, 171-191, 2016.

[23] Online Available from https://www.propublica.org/article/livi ng-apart-how-the-government-betrayed-a-landmark-civil-rig hts-law

[24] D. W. Sue, C. M. Capodilupo, G. C. Torino, J. M. Bucceri, A. M. B. Holder, K. L. Nadal, and M. Esquilin, Racial microaggressions in everyday life: Implications for clinical practice, American Pyschologist, Vol. 62, No. 4, 271-286, 2007.

[25] J. Feagin, Systemic racism: A theory of oppression, Routledge, America, 2013.

[26] Online Available from http:/www.theatlantic.com/politics/ar chive/2015/12/hope-and-the-historian/419961/

[27] S. Hall, Race, The floating Signifier, Media Education Foundation, Northampton, MA, 1997.

[28] D. A. Norman, The way I see it: Signifiers, not affordances, interactions, Vol. 15, No. 6, 18-19, 2008.

[29] L. Adelman, Unnatural Causes: Is inequality making us sick?, California Newsreel, 2008.

[30] N. A. Mansukhani, D. Y. Yoon, K. A. Teter, V. C. Stubbs, I. B. Helenowski, T. K. Woodruff, M. R. Kibbe, Determining if sex bias exists in human surgical clinical research, JAMA surgery, Vol 151, No. 11, 1022-1030, 2016.

[31] M. Knuttila, Introducing Sociology: A Critical Approach, $4^{\text {th }}$ ed., Oxford University Press, Ontario, 2008.

[32] J. Feagin, Systemic racism: A theory of oppression, Routledge, America, 2013.

[33] S. Hall, Signification, representation, ideology: Althusser and the post-structuralist debates, Critical Studies in Mass Communication, Vol. 2, No. 2, 91-114, 1985. 
[34] Online Available from http://www.tennessean.com/story/new s/2016/07/14/cory-batey-faces-least-15-years-friday-sentenci $\mathrm{ng} / 86953944 /$

[35] Online Available from http://www.cnn.com/2016/09/02/us/br ock-turner-release-jail/

[36] T. Coates, The case for reparations, The Atlantic, 2014.

[37] Online Available from http://connecticuthistory.org/the-effect s-of-redlining-on-the-hartford-metropolitan-region/

[38] J. R. Mercer, A policy statement on assessment procedures and the rights of children, Harvard Educational Review, Vol. 44, No. 1, 125-141, 1974.

[39] L. Zoref, P. Williams, A look at content bias in IQ tests, Journal of Educational Measurement, Vol. 17, No. 4, 313-322, 1980.

[40] T. Fabelo, M. D. Thompson, M. Plotkin, D. Camichael, M. Marchbanks III, E. A. Booth, Breaking schools' rules: A statewide study of how school discipline relates to students' success and juvenile justice involvement, Council of State Governance Justice Center, New York, 2011.

[41] Online Available from http://www.nytimes.com/interactive/2 016/11/08/us/politics/election-exit-polls.html?_r=0

[42] M. Kohan, Personal Communication via email; PDT assignment, 2016.

[43] H.R. Milner IV, Race, culture, and researcher positionality: Working through dangers seen, unseen, and unforeseen, Educational Researcher, Vol. 36, No. 7, 388-400, 2007.

[44] G. Cunningham, Understanding diversity in intercollegiate athletics, Journal for the Study of Sports and Athletes in Education, Vol. 2, No. 3, 321-338, 2008.

[45] L. Hoeber, S. Kerwin, Exploring the experiences of female sport fans: A collaborative self-ethnography, Sport Management Review, Vol. 16, 326-336, 2013.

[46] D. Strum, Playing with the autoethnographical: Performing and re-presenting the fan's voice, Critical Methodologies, Vol. $15,213-223,2015$.

[47] A. Pavlidis, S. Fullagar, Sport, Gender and Power: The Rise of Roller Derby, Ashgate Publishing Limited, Surrey, England, 2014.

[48] A.C. Sparkes, Athletic identity: An Achilles' heel to survival of self, Qualitative Health Research, Vol. 8, 644-664, 1998.

[49] J. Cooper, R. S. Grenier, C. Macaulay, Autoethnography as a critical approach in sport management: Current applications and directions for future research, Sport Management Review, In Press.

[50] N.K. Denzin, Analytic autoethnography, or déjà vu all over again, Journal of Contemporary Ethnography, Vol. 35, 419-428, 2006

[51] [54] J. Cooper, R. S. Grenier, C. Macaulay, Autoethnography as a critical approach in sport management: Current applications and directions for future research, Sport Management Review, In Press.

[52] C. Ellis, T.E. Adams, A.P. Bochner, Autoethnography: An overview, Forum Qualitative Sozialforschung, Vol. 12, 273-290, 2011.
[53] T. Spry, Performing autoethnography: An embodied methodological praxis, Qualitative Inquiry, Vol. 7, 706-732, 2001.

[54] T. Wise, White Like Me: Reflections on Race from a Privileged Son, Soft Skull Press, Berkeley, California, 2008.

[55] S. H. Razack, Race, Space, and the Law: Unmapping a White Settler Society, Between the Lines, Ontario, Canada, 2002.

[56] V. Satzewich, N. Liodakis, 'Race' and Ethnicity in Canada: A Critical Introduction, $2^{\text {nd }}$ Ed., Oxford University Press, New York, 2010

[57] R. D. Chrisjohn, S. L. Young, M. Maruan. The circle game: shadows and substance in the Indian residential school experience in Canada. Theytus Books Penticton, B.C. 1997.

[58] M. Alexander, The new Jim Crow: Mass incarceration in the age of colorblindness. The New Press, New York, 2012.

[59] M. Mauer, R. S. King, Uneven justice: State rates of incarceration by race and ethnicity, The Sentencing Project, Washington, D.C., 2007.

[60] T. Fabelo, M. D. Thompson, M. Plotkin, D. Camichael, M. Marchbanks III, E. A. Booth, Breaking schools' rules: A statewide study of how school discipline relates to students' success and juvenile justice involvement, Council of State Governance Justice Center, New York, 2011.

[61] D. W. Sue, C. M. Capodilupo, G. C. Torino, J. M. Bucceri, A. M. B. Holder, K. L. Nadal, and M. Esquilin, Racial microaggressions in everyday life: Implications for clinical practice, American Pyschologist, Vol. 62, No. 4, 271-286, 2007.

[62] J. Coakley, Race and ethnicity: Are they important in sports? Sports in Society: Issues and Controversies, $10^{\text {th }} \mathrm{ed}$., McGraw-Hill, New York, 2009.

[63] M. Mauer, Race to incarcerate: The causes and consequences of mass incarceration, Roger Williams University Law Review, Vol. 21, No. 2, 447-470, 2016.

[64] K. A. Johnson, K. L. Johnson, 'Looking like Trayvon': The narratives we tell about race, (Re)teaching Trayvon: Education for Racial Justice and Human Freedom, Sense Publishers, Boston, 2014.

[65] H.R. Milner IV, Race, culture, and researcher positionality: Working through dangers seen, unseen, and unforeseen, Educational Researcher, Vol. 36, No. 7, 388-400, 2007.

[66] C. Titone, Educating the White teacher as Ally, White Reign: Deploying Whiteness in America, St. Martin's Press, New York, 1998.

[67] P. McIntosh, White privilege: Unpacking the invisible knapsack, Race, class, and gender in the United States: An integrated study, Vol. 4, 165-169, 1988.

[68] P. Freire, Pedagogy of the Oppressed, Penguin Books, London, England, 1996.

[69] R. A. Buford May, When the methodological shoe is on the other foot: African American interviewer and White interviewees, Qualitative Sociology, Vol. 37, No. 1, 117-136, 2014. 
[70] D.D. Bernal, Critical race theory, Latino critical theory, and critical raced-gendered epistemologies: Recognizing students of color as holders and creators of knowledge, Qualitative Inquiry, Vol. 8, No. 1, 105-126, 2002.
[71] P. McIntosh. How studying privilege systems can strengthen compassion. At TEDx - Timberlane Schools. Online Available from:https://www.youtube.com/watch?v=e-BY9U EewHw 